\title{
The effects of dynamic pressure on the stability of prepared drifts near the working surface areas
}

\author{
Nhan Thi Pham*, Nghia Viet Nguyen \\ Hanoi University of Mining and Geology, Vietnam
}

\begin{tabular}{|c|c|}
\hline ARTICLE INFO & ABSTRACT \\
\hline $\begin{array}{l}\text { Article history: } \\
\text { Received 25th } \text { Oct. } 2020 \\
\text { Revised } 23^{\text {rd }} \text { Jan. } 2021 \\
\text { Accepted } 06^{\text {th }} \text { Feb. } 2021\end{array}$ & $\begin{array}{l}\text { Due to the effects of dynamic pressure, the stress distribution of rock mass } \\
\text { is very complex. The reason for this could be a risk of stability loss for an } \\
\text { auxiliary tunnel system constructed within the study area. In this article } \\
\text { by using Flac }{ }^{3 D} \text { software the author simulated two adjacent working faces }\end{array}$ \\
\hline $\begin{array}{l}\text { Keywords: } \\
\text { Auxiliary tunnel, } \\
\text { Coal pillar, Displacement, } \\
\text { Pressure. }\end{array}$ & $\begin{array}{l}\text { with the thickness of } 5 \mathrm{~m} \text { natural coal pillar. Three factors: the upper } \\
\text { working face excavation process, auxiliary tunnel mining process, and the } \\
\text { location of lower working face, affected by deformation, stress } \\
\text { distribution, safety of lower floor area and surrounding rock mass of } \\
\text { tunnel. The research results show that during the excavation, the } \\
\text { mechanical behavior of the rock mass surrounding the auxiliary tunnel } \\
\text { showed displacements, volatility, and phase characteristic. The } \\
\text { displacement on the auxiliary tunnel boundary in both excavation and } \\
\text { working face cases showed that the roof and the left side wall } \\
\text { displacement was greater than the right side wall and the bottom. } \\
\text { Therefore, the distance between the auxiliary tunnel and the empty } \\
\text { mining space needs to be computed to meet technical and economic } \\
\text { requirements. }\end{array}$ \\
\hline
\end{tabular}

Copyright (C) 2021 Hanoi University of Mining and Geology. All rights reserved.

${ }^{*}$ Corresponding author

E-mail: phamthinhan@humg.edu.vn

DOI: 10.46326/JMES.2021.62(1).10 


\title{
Nghiên cứu ảnh hưởng tải trọng động đến ổn định của đường lò chuẩn bị nằm trong khu vực lò chợ hoạt động
}

\author{
Phạm Thị Nhàn *, Nguyễn Viết Nghĩa \\ Trường Đại học Mỏ - Địa chất, Hà Nội, Việt Nam
}

\begin{tabular}{|c|c|}
\hline THÔNG TIN BÀI BÁO & TÓM TẮT \\
\hline $\begin{array}{l}\text { Quá trình: } \\
\text { Nhận bài } 25 / 10 / 2020 \\
\text { Sưa xong } 23 / 01 / 2020 \\
\text { Chấp nhận đăng 06/02/2021 }\end{array}$ & 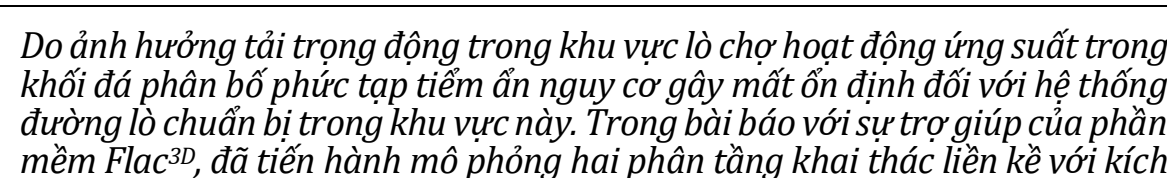 \\
\hline $\begin{array}{l}\text { Tù khóa: } \\
\text { Chuyển vị, } \\
\text { Lò chuẩn bị, } \\
\text { Trụ bảo vệ, } \\
\text { Ứng suất. }\end{array}$ & 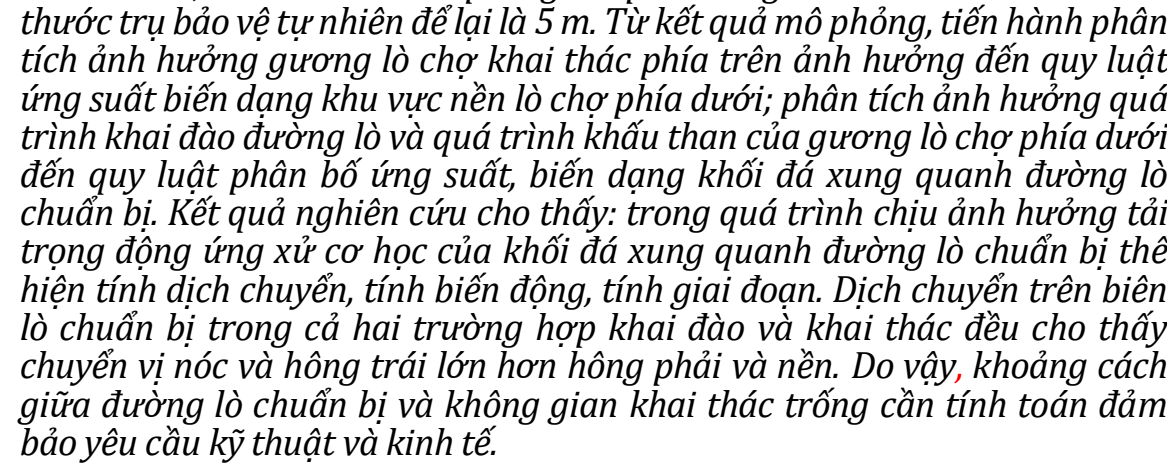 \\
\hline
\end{tabular}

C 2021 Trường Đại học Mỏ - Địa chất. Tất cả các quyền được bảo đảm.

\section{Mở đầu}

Công tác chống giữ ổn định đường lò là một trong những khâu quan trọng trong quá trình khai thác than. Để đảm bảo khai thác khoáng sản thuận lợi, các đường lò được đào, chống và đảm bảo ổn định trong suốt thời gian phục vụ. Áp lực động trong quá trình khai thác lò chợ sẽ tác động trực tiếp hoặc gián tiếp đến các đường lò chuẩn bị khai

\section{*Tác giả liên hẹ}

E- mail: phamthinhan@humg.edu.vn

DOI: 10.46326/JMES.2021.62(1).10 thác nằm trong khu vực này. Thực tế cho thấy, khả năng áp dụng công nghệ khai thác và hiệu quả thực hiện công nghệ phụ thuộc rất lớn vào điều kiện địa chất mỏ (Nguyễn Phi Hùng và nnk, 2020). Trong quá trình khai thác, dưới tác dụng của áp lực cao, các tai nạn động lực do hoạt động khai thác than gây ra có liên quan mật thiết đến môi trường địa cơ học và ứng xử cơ học của khối đá xung quanh đường lò. Ứng suất thứ sinh trong quá trình khai thác là động lực, nguyên nhân cơ bản của các tai biến liên quan đến tải trọng động. Sự biến đổi ứng suất có thể gây ra sự dịch chuyển và biến dạng của lớp đá, sự phá hủy lớp đá và sự mất 
ổn định cấu trúc. Sự biến đổi này còn là nguyên nhân trực tiếp dẫn đến sự biến dạng lớn của khối đá xung quanh đường lò và tụt lở nóc lò. Chính vì vậy, cần thiết phải tiến hành nghiên cứu phân tích ổn định các đường lò trong khu vực khai thác dưới ảnh hưởng tải trọng động.

Trong bài báo với sự trợ giúp của phần mềm Flac ${ }^{3 D}$, các tác giả đã tiến hành mô phỏng quy luật phân bố ứng suất, biến dạng khối đá xung quanh đường lò trong khu vực khai thác, có chúý đến yếu tố ảnh hưởng tải trọng động do khấu than khu vực lò chợ.

\section{Khu vực nghiên cứu dữ liệu}

Cácgương lò sau khi tiến hành khấu than, phần đá trên nóc lò không nhưng phát sinh tụt lún mà trên chu vi biên vùng khai thác trống sẽ phát sinh đứt gãy, phần trụ than để lại không thể đảm bảo ổn định. Phần dầm đá phía nóc lò có thể sẽ lún dần về khoảng khai thác trống làm phát sinh biến dạng, áp lực tựa dịch chuyển sâu vào trong khối than và hình thành vùng phá hủy dẻo. Trong quá trình khai đào và sau khi kết thúc khai đào đường lò, sự phân bố áp lực tựa có sự thay đổi lớn, thông qua việc để lại các trụ bảo vệ sẽ có lợi trong việc bảo vệ các đường lò phụ trợ. Tuy nhiên, dưới ảnh hưởng tải trọng động do khai thác, trong bản thân các trụ bảo vệ hình thành các vi khe nứt phát triển mạnh mẽ, khiến khả năng tự chống giữ, tự ổn định khá thấp.

Hiện nay có nhiều phương thức khai thác than (khai thác theo phương pháp hạ trần, khai thác không trụ bảo vệ, khai thác có tầng bảo vệ,...). Dù sử dụng phương pháp khai thác nào thì khối than đá phía trước gương lò cũng chịu ảnh hưởng bởi các chấn động, biến đổi từ trạng thái ứng suất nguyên sinh sang trạng thái ứng suất thứ sinh, trong đó ứng suất hướng trục $\left(\sigma_{1}-\sigma_{3}\right)$ tăng cao nhưng áp lực $\sigma_{3}$ thì lại giảm (Heping Xie và nnk., 2015). Hình 1 đưa ra trạng thái ứng suất khối đá than phía trước gương lò khai thác, giá trị áp lực biến đổi tùy thuộc vào 3 loại hình khai thác phổ biến. Giả sử $\alpha$ là hệ số tập trung áp lực do ảnh hưởng của các hình thức khai đào hoặc khấu than khác nhau, áp lực khối than phía trước gương đào chịu ảnh hưởng tải trọng động trước khi phá hủy dỡ tải có thể đạt được như sau:

$$
\sigma_{1}=\alpha_{r} \cdot H
$$

Trong đó: $\gamma$ - dung trọng $\left(\mathrm{kN} / \mathrm{m}^{3}\right), H$ - độ sâu khai thác $(\mathrm{m})$.

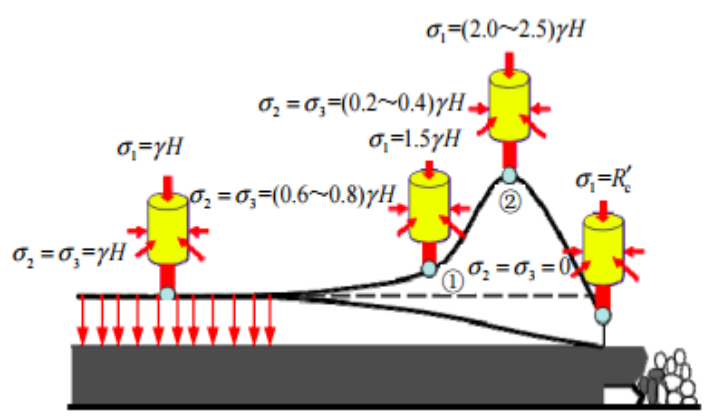

Hình 1. Trạng thái úng suất khối đá than phía trước gương đào khi khai thác bằng phưong pháp hạ trần (Heping Xie và nnk., 2015).

Trong đó, giá trị $\alpha$ tùy thuộc vào phương thức khai thác: Phương pháp sử dụng tầng bảo vệ, khai thác hạ trần, khai thác không trụ bảo vệ trị số $\alpha$ lấy lần lượt là 2,0;2,5;3,0; đồng thời $\sigma_{1}$ cũng tăng dần từ $\gamma H$ đến $\alpha \gamma H$. Giá trị $\sigma_{2}-\sigma_{3}$ sẽ đối ứng với điểm 1 và 2 trong Hình 1 , ứng suất ngang khi chịu tải trọng động được biểu thị như sau, (Heping Xie và nnk., 2015):

$$
\begin{gathered}
\sigma_{2}=\sigma_{3}=\frac{2}{5} \sigma_{1} \\
\sigma_{2}=\sigma_{3}=\frac{1}{5 \alpha} \sigma_{1}(\sigma=2.0 ; 2.5 ; 3.0)
\end{gathered}
$$

Trong công thức trên, trạng thái ứng suất cơ học động của khối đá than phía trước gương lò, đã được xem xét đến sự ảnh hưởng của phương thức khai đào hoặc khấu than, đồng thời cũng xem xét tới sự ảnh hưởng của độ sâu khai thác đến trạng thái cơ học động trong khối đá than. Như vậy, các biểu hiện cơ học của khối đá khi chịu ảnh hưởng chấn động do khai thác so khi gia tải đơn thuần truyền thống có sự khác biệt rõ rệt.

\section{Lập mô hình và các thông số đầu vào}

\subsection{Tiêu chuẩn bền}

Mô hình cơ học phản ánh tính chất cơ học cơ bản của vật liệu, đất đá, thể hiện mối quan hệ giữa ứng suất - biến dạng đá dưới tác dụng của tải trọng. Vì vậy, lựa chọn mô hình cơ học hợp lý thì mới mô phỏng chính xác tính chất cơ học của vật liệu, đất đá công trình. Trong mô hình mô phỏng sử dụng tiêu chuẩn bền Mohr - Coulomb (Yang Ke và nnk., 2009):

$$
f_{s}=\sigma_{1}-\sigma_{3} \frac{1+\sin \varphi}{1-\sin \varphi}+2 c \sqrt{\frac{1+\sin \varphi}{1-\sin \varphi}}
$$

Trong đó: 
Trong đó:

$\sigma_{1}$ - ứng suất chính lớn nhất;

$\sigma_{3}$ - ưng suất chính nhỏ nhất;

$c$ - lực dính kết; $\varphi$ - góc ma sát trong.

Khi $f_{s}<0$ phần tử đất đá sẽ phát sinh phá hoại.

\subsection{Kích thước mô hình và tính chất cơ lý các lớp đá, than}

Mô hình mô phỏng có 5 lớp đất đá, kích thước của mô hình theo các chiều lần lượtlà 160 × 80×60 m.

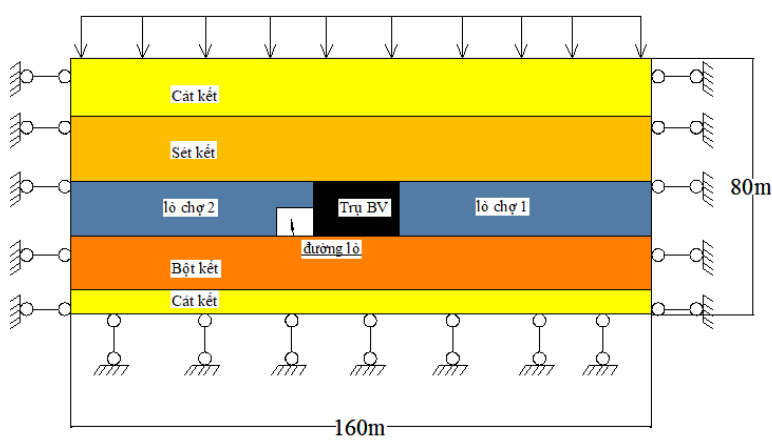

Hình 2. Điều kiện biên mô hình

Mặt trên mô hình là mặt tự do đặt tải trọng phân bố đều, tải trọng này chính là tải trọng của các lớp đất đá phía trên tác dụng lên. Khi đó, tải trọng tác dụng lên mặt trên mô hình là $q=H x \gamma$, $\mathrm{MPa}$ ( $\gamma$ - trọng lượng thể tích lớp đất đá phía trên,
Mô hình sau khi chia lưới gồm gồm 96.443 ô lưới và 121.890 nút như thể hiện Hình 2.

Để đơn giản hóa công việc xây dựng lưới mô hình, yếu tố hình dạng đường lò không được xét đến và lựa chọn tiết diện đường lò chuẩn bị là loại hình tiết diện hình chữ nhật có kích thước rộng x cao là 5,0×4,8 m được để lưu không nhằm khảo sát ảnh hưởng hoạt động khấu than từ gương lò chợ số 1.

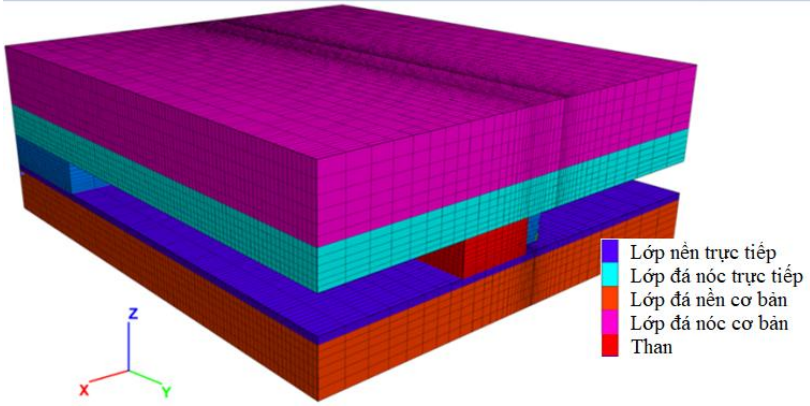

Hình 3. Mô hình trên phần mềm Flac ${ }^{3 D}$

lấy tương đối bằng $25 \mathrm{Kn} / \mathrm{m}^{3}, H$ - chiều sâu đặt công trình). Mặt dưới và hai mặt bên được cố định, mô hình bài toán được thể hiện như trên Hình 2 và Hình 3 . Tính chất cơ lý các lớp đá than được thể hiện như trên Bảng 1.

Bảng 1. Tính chất co lý của các lớp đá, than.

\begin{tabular}{|c|c|c|c|c|c|}
\hline Tên đá & $\begin{array}{c}\text { Mật độ } \\
\left(\mathrm{Kgm}^{-3}\right)\end{array}$ & $\begin{array}{c}\text { Cường độ kháng nén } \\
(\mathrm{MPa})\end{array}$ & $\begin{array}{c}\text { Cường độ kháng kéo } \\
(\mathrm{MPa})\end{array}$ & $\begin{array}{c}\text { Mô đun đàn hồi } \\
(\mathrm{GPa})\end{array}$ & $\begin{array}{c}\text { Poisson's } \\
\text { ratio }\end{array}$ \\
\hline Cát kết hạt mịn & 2600 & 48,45 & 4,0 & 25,4 & 0,22 \\
\hline Sét kết & 2500 & 24,37 & 2,37 & 12,96 & 0,17 \\
\hline Than & 1440 & 10,08 & 3,72 & 3,97 & 0,3 \\
\hline Sét kết chặt vừa & 2500 & 27,0 & 2,0 & 12,96 & 0,17 \\
\hline Cát kết hạt trung & 2600 & 54,0 & 4,0 & 35,40 & 0,22 \\
\hline
\end{tabular}

Quá trình đào lò chuẩn bị được tiến hành mỗi bước khai đào là $1 \mathrm{~m}$, tổng cộng gồm 20 bước. Sau khi lò chợ số 1 được khai đào xong toàn bộ, lò chợ số 2 được khấu than với khẩu độ $1 \mathrm{~m}$.

\section{Phân tích kết quả mô phỏng số}

\subsection{Phân tích ảnh hưởng quá trình khấu than gương lò chợ số 1 ảnh hưởng đến nền khu vực đường lò chuẩn bị}

Trong quá trình đào lò, dưới ảnh hưởng tải trọng động, trạng thái cân bằng của ứng suất nguyên sinh khối đá/than bị phá vỡ, Hình 4 thể hiện sự phân bố ứng suất nền lò sau khi gương lò chợ số 1 khấu than. Trong đó, $\mathrm{x}=0 \mathrm{~m}$ là tại vị trí gương lò, phía vách trụ than là $\mathrm{x} \geq 7,2 \mathrm{~m}$, phần gương lò chợ số 2 là $x<7,2 \mathrm{~m}$. Từ Hình 3 nhận thấy, do ảnh hưởng hoạt động khấu than gương lò số 1 , khu vực nền lò phía gương lò chợ số 2 có hiện tượng tập trung ứng suất rõ rệt. Phần chính giữa khu vực khai trác trống do lún trực tiếp, đất đá được giảm tải nên ứng suất thẳng góc được khôi phục laai trạng thái ổn định ban đầu. Như vậy, có thể thấy việc khai thác gương lò chợ số 1 có ảnh 


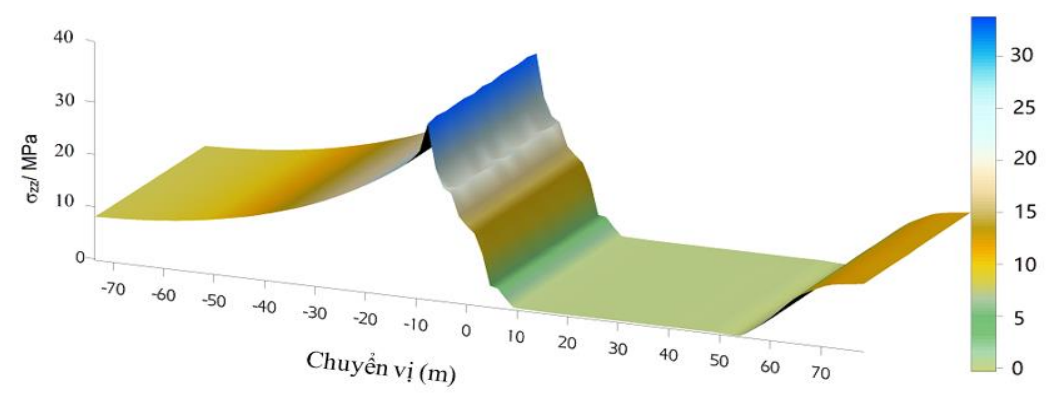

Hình 4. Phân bố úng suất thẳng góc tại nền các khu vực lân cận khi chịu ảnh hưởng khai thác gưong lò chợ số 1.

hưởng lớn đến ứng suất thẳng góc đất đá khu vực gương lò chợ số 2 , ứng suất thẳng góc cực đại gấp 3,26 lần ứng suất nguyên sinh ban đầu, vị trí ứng suất cực đại cách trụ than khoảng 13,4 m đạt 30,107 MPa. Từ Hình 5 cho thấy, hoạt động khai thác của gương lò chợ số 1 cũng gây ảnh hưởng đến ứng suất ngang tại nền khu vực gương lò chợ số 2 , ứng suất $\sigma_{\mathrm{xx}}$ đạt cực đại tại vị trí khoảng $14,5 \mathrm{~m}$.

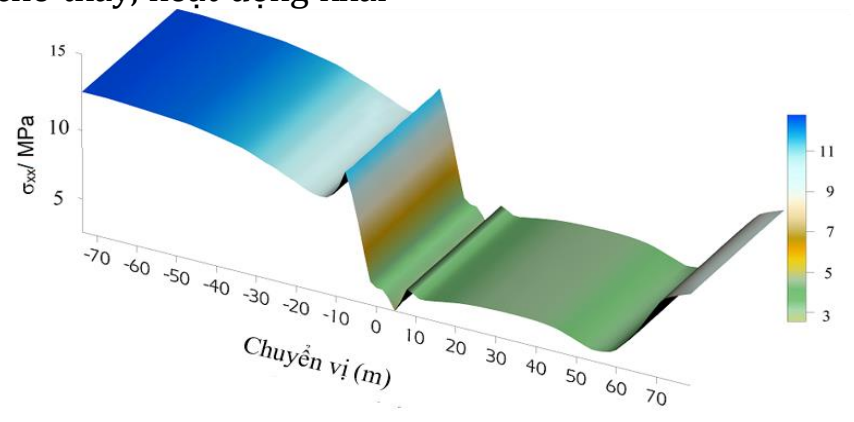

Hình 5. Phân bố úng suất ngang tại nền các khu vực lân cận khi chịu ảnh hưởng khai thác gưong lò chợ số 1.

Nhiều nghiên cứu trước đây cho rằng lân cận khu vực ứng suất thẳng đứng cực đại rất dễ làm tăng biến dạng nóc và hai bên hông lò, lân cận khu vực ứng suất ngang cực đại có nhiều khả năng phát sinh bùng nền (Xia Jingchao, 2019). Tuy nhiên, các nghiên cứu trước đây về trụ bảo vệ tự nhiên dọc vùng khai thác trống thường chỉ chú ý nhiều đến vị trí ứng suất thẳng góc cực đại, đường lò chuẩn bị sẽ bố trí tránh vị trí này mà không chú ý nhiều đến vị trí và sự ảnh hưởng của ứng suất ngang cực đại. Đặc biệt, với những đường lò chuẩn bị chống giữ bằng vì neo lưới thép vốn dĩ kháng ứng suất ngang kém, bởi vậy việc chú ý đến kích thước trụ bảo vệ và chủ động xác định vị trí lò chuẩn bị tránh khu vực tập trung ứng suất hông lớn là điều hết sức cần thiết.

\subsection{Phân tích ảnh hưởng tải trọng động đến ổn định đường lò chuẩn bị}

\subsubsection{Quy luật phân bố úng suất và biến dạng đường lò chuẩn bị trong quá trình khai đào}

Công tác chống giữ đường lò là việc thực hiện các biện pháp kiểm soát khối đá xung quanh đường lò khi khối đá không có điều kiện tự ổn định, việc chống giữ phải được thực hiện trên cơ sở nắm bắt được đặc tính phá hủy khối đá xung quanh đường lò và các quy luật cơ học khác. Do vậy, việc xác định các nguyên tắc chống giữ hợp lý cho đường lò có ý nghĩa hết sức quan trọng (Bai Jian Biao, 2002; Xia Jingchao, 2019; XU Zhu-he, 2020). Trong quá trình đào lò, ứng xử cơ học của khối đá xung quanh đường lò chuẩn bị thể hiện tính dịch chuyển, tính biến động, tính giai đoạn cụ thể như sau:

Tính dịch chuyển: sự phân bố ứng suất thẳng góc trong khối đá xung quanh đường lò từ khi bắt đầu đào và sau khi kết thúc quá trình đào lò được thể hiện trên Hình 6 . Từ hình vẽ có thể thấy, vùng tập trung ứng suất thẳng góc bên hông trái từ khi bắt đầu đến khi kết thúc quá trình khai đào sẽ tăng lên về giá trị và có xu hướng di chuyển dần lên cao. Mặt khác trong quá trình đào lò, phần khối đá xung quanh biên lò được giảm tải, bên hông phải đường lò vùng ứng suất cực đại có xu hướng dịch chuyển dần về phía không gian khai thác trống của gương lò chợ số 1. 


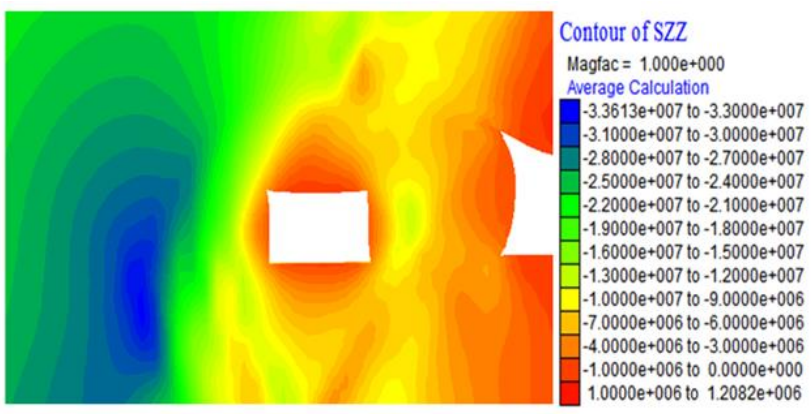

(a) Bắt đầu khai đào

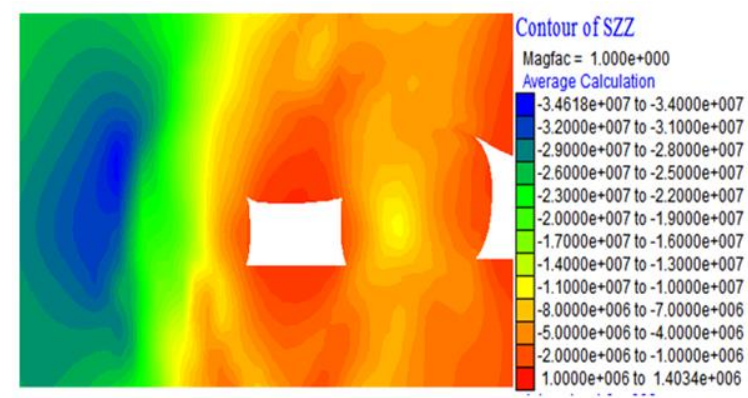

(b) Khai đào kết thúc

Hình 6. Phân bố úng suất thẳng góc khối đá trong quá trình đào lò chuẩn bị.

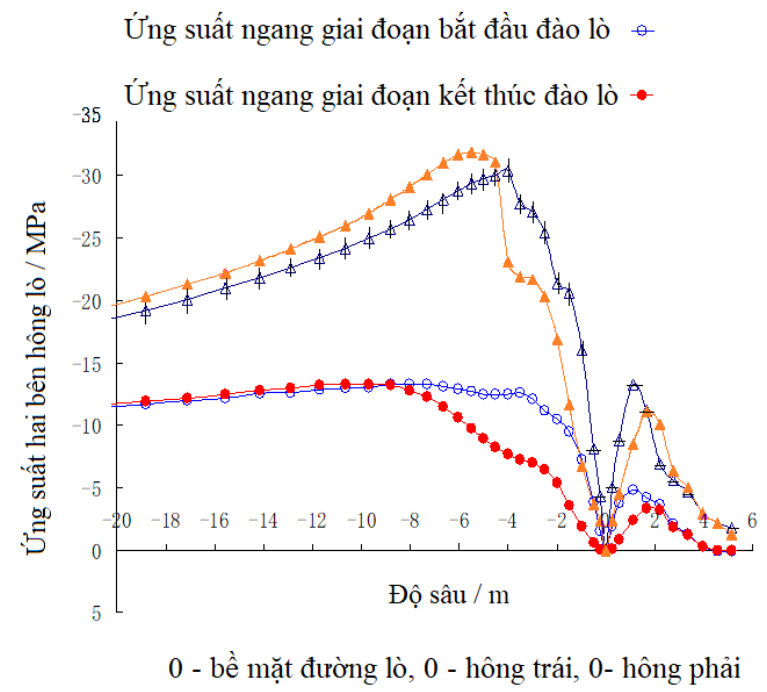

(a) Hai bên hông lò

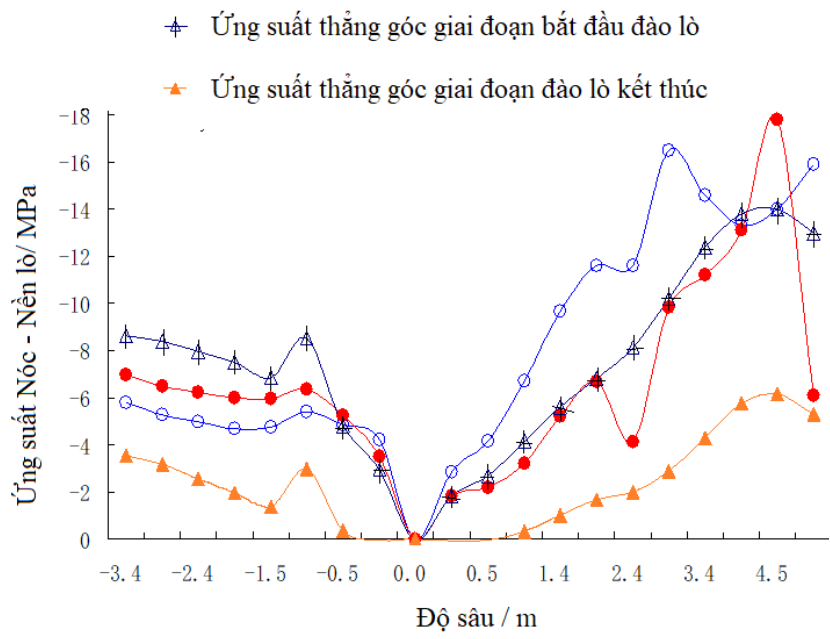

0 - bề mặt đường lò, 0 - hông trái, 0 - hông phải

(b) nóc - nền lò

Hình 7. Biến đổi úng suất khối đá trong quá trình khai đào.

Tính biến động thể hiện như sau: trên Hình 7 thể hiện sự biến đổi ứng suất khối đá xung quanh đường lò cách phía trước gương khảo sát $1 \mathrm{~m}$ và sau gương khảo sát $16 \mathrm{~m}$, bố trí mặt cắt khảo sát tại vị trí $\mathrm{y}=10 \mathrm{~m}$. Từ hình này có thể thấy, đường lò sau khi đào tại phía trên nóc có sự tập trung ứng suất ngang. Theo tốc độ tiến gương ứng suất này giảm đi và vùng tập trung ứng suất có xu hướng dịch chuyển sâu vào trong nội bộ khối đá. Ảnh hưởng của quá trình đào lò làm cho quá trình giảm ứng suất thẳng góc nhanh hơn ứng suất hông. Do vậy, sau khi kết thúc quá trình đào lò, ứng suất hông lớn hơn ứng suất thẳng góc.

Từ Hình 8 cũng cho thấy, ảnh hưởng tải trọng động của quá trình đào lò thay đổi liên tục, giá trị ứng suất cực đại trong khối đá cũng liên tục điều chỉnh. Giá trị ứng suất ngang cực đại tại không ngừng di chuyển vào sâu bên trong khối đá. Trong khi đó, tại nóc và nền lò, sự biến đổi giá trị lớn nhỏ của ứng suất ngang và thẳng góc là chủ yếu còn vị trí ứng suất cực đại biến đổi không lớn.

Tính giai đoạn: quy luật biến đổi của chuyển vị khối đá trong quá trình đào lò thể hiện như Hình $7 \mathrm{a}$, trong đó chuyển vị nóc lò lớn nhất 0,35 $\mathrm{m}$ sau đó là hông trái $0,27 \mathrm{~m}$, hông phải $1,15 \mathrm{~m}$ và cuối cùng là nền lò $0,25 \mathrm{~m}$. Chuyển vị nóc, hông trái - phải phát triển liên tục trong suốt quá trình đào lò, ngược lại với nền lò phát triển nhanh giai đoạn đầu sau đó gần như ổn định, sự thay đổi không đáng kể. Chuyển vị hông trái lớn hơn hông phải $1,6 \div 1,8$ lần, chứng tỏ vị trí bố trí đường lò chuẩn bị là hợp lý, tránh được vùng tập trung ứng suất khi tiến hành khai thác lò chợ số 1 . 


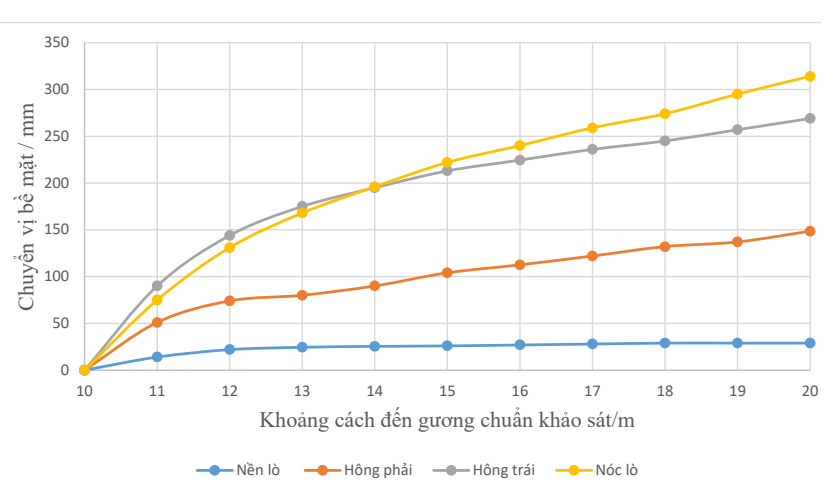

(a) đào lò chuẩn bị

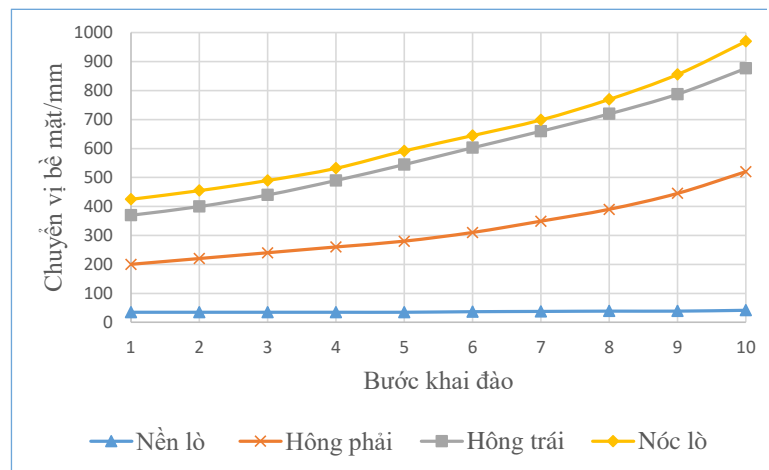

(b) khai thác gương lò chợ số 2

Hình 8. Thể hiện quá trình biến đổi chuyển vị trên biên đường lò.

\subsubsection{Quy luật phân bố ứng suất và biến dạng đường lò chuẩn bị trong quá trình gương lò chợ số 2 khai thác}

Trong suốt quá trình khấu than, bản thân khối đá trải qua nhiều lần chịu ảnh hưởng tải trọng: một là ảnh hưởng tải trọng động do khấu gương lò chợ số 1 , hai là quá trình đào lò chuẩn bị, ba là khi gương lò chợ số 2 hoạt động sẽ làm cho trạng thái cơ học khối than/đá liên tục được điều chỉnh mạnh mẽ. Trong đó, phía bên hông phải lò chuẩn bị chịu ảnh hưởng là mạnh nhất. Khi gương lò được đẩy dần theo tiến độ thi công, hình thành vùng áp lực động vượt trước được đẩy dần lên (Hình 8), ứng suất hông phải đường lò chuẩn bị biến đổi theo quy luật tăng trước giảm sau. Khi kích thước trụ bảo vệ tự nhiên $5 \mathrm{~m}$, vùng ứng suất tập trung phía hông phải đường lò chuẩn bị cách khoảng $7 \mathrm{~m}$, bản thân trong trụ bảo vệ cũng có vùng tập trung ứng suất cách biên lò khoảng $2 \mathrm{~m}$.

Tại khu vực nền lò chuẩn bị, ứng suất hướng tâm giảm tải, ứng suất ngang tăng lên, đây chính là nguyên nhân gây ra hiện tượng bùng nền thường xuất hiện khi ảnh hưởng của tải trọng động do khai thác quá lớn.

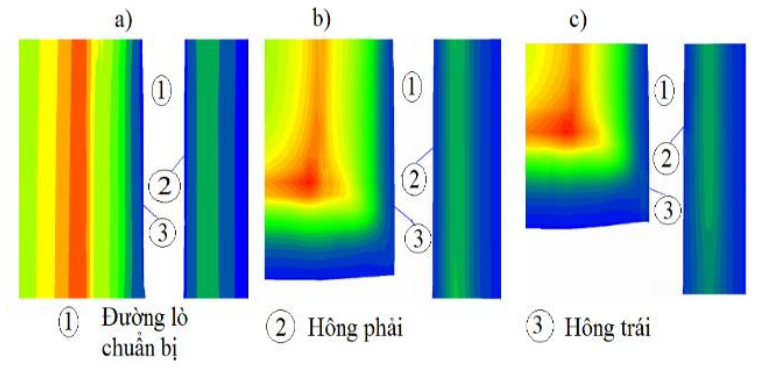

Hình 9. Phân bố áp lực khối đá trong quá trình khai thác.

a) đào lò chuẩn bị xong, b) bắt đầu khai thác, c) khai thác được $12 \mathrm{~m}$.
Trong giai đoạn khai thác lò chợ số 2 , chuyển vị hội tụ tăng lên rõ rệt (Hình 9b). So với thời điểm tiến hành đào lò chuẩn bị, lượng chuyển vị nóc lò tăng 209\%, nền lò $27 \%$, hông trái $228 \%$ và hông phải $252 \%$. Như vậy, dịch chuyển trên biên lò trong cả hai trường hợp đào lò và khai thác đều cho thấy chuyển vị nóc và hông trái lớn hơn hông phải và nền, do vậy việc lựa chọn kích thước trụ bảo vệ tự nhiên cần phải được lựa chọn hợp lý đảm ổn định cho các đường lò chuẩn bị an toàn và ít tổn thất về mặt kinh tế.

\section{Kết quả}

Trên cơ sở những phân tích trên thấy rằng quy luật phân bố ứng suất trong khối đá khu vực lò chợ hoạt động phân bố rất phức tạp, phụ thuộc vào rất nhiều yếu tố như điều kiện địa chất, phương thức khai thác, công nghệ khai thác,... Các đường lò chuẩn bị trong khu vực lò chợ hoạt động dưới ảnh hưởng của tải trọng động biểu hiện các đặc điểm như sau:

Khi khai thác gương lò chợ số 1 , ứng suất thẳng góc và ứng suất ngang khu vực nền gương lò chợ số 2 đều có sự tập trung ứng suất với giá trị lớn hơn nhiều lần giá trị ứng suất nguyên sinh.

Trong quá trình đào lò, ứng xử cơ học của khối đá xung quanh đường lò chuẩn bị thể hiện tính dịch chuyển, tính biến động, tính giai đoạn.

Khi gương lò chợ số 2 hoạt động do ảnh hưởng tải trọng động thay đổi liên tục, ứng suất liên tục điều chỉnh gây ra vùng tập trung ứng suất ngang và ứng suất thẳng đứng trong khối đá xung quanh đường lò chuẩn bị, là nguyên nhân gây ra biến dạng lớn như tụt nóc, lở hông hoặc bùng nền.

Dịch chuyển trên biên lò trong cả hai trường hợp đào lò và khai thác đều cho thấy chuyển vị nóc 
và hông trái lớn hơn hông phải và nền. Do vậy, khoảng cách đường lò chuẩn bị và không gian khai thác trống cần được tính toán đảm bảo yêu cầu kỹ thuật và kinh tế.

\section{Đóng góp của các tác giả}

Tác giả Phạm Thị Nhàn: lập mô phỏng số, phân tích viết bài.

Tác giả Nguyễn Viết Nghĩa: hiệu chỉnh, phân tích dữ liệu trích xuất từ mô hình.

\section{Tài liệu tham khảo}

Bai, J. B. (2002). Nghiên cưu nguyên lý và công nghệ điều khiển ổn định khối đá xung quanh đường lò chuẩn bị khi khai thác bằng cơ giới hóa hoàn toàn. Luận văn tiến sĩ, Đại học Mỏ Công nghệ, Từ Châu, Trung Quốc.

Itasca. (2005). Flac Fast Lagrangian analysis of continua. User's guide. Third edition.

Heping, X., Gao F., and Ju, Y.. (2015). ResearchResearch and development of rock mechanics in deep ground engineering. Chinese Journal of Rock Mechanics and Engineering, $\quad 34(11), 2161-2178$.
Nguyễn, P. H., Nguyen, C. K., Bùi, M. T., Lại, Q. T., Tran. V. T. (2020). Giải pháp nâng cao hiệu quả chống giữ cho lò chợ cơ giới hóa vỉa 6 mỏ than Nam Mẫu. Tạp chí khoa học kỹ thuật Mỏ - Địa chất, 61(1), 116-123.

Yang, K., Xie, G. X, Chang, J. C. (2009). Study on the stability of rock surrounding gateway with different coal - pilar widths. Chinese Jounal of Underground Space and Engineering, 5, 991-996.

Xia, J. C. (2019). Research on the influence of repeated mining on Tunnel safety and Its control measure. North China University of Technology.

Xu, Z., Xiao, P., Li, X. B. (2020). Study on Control Technology of Roadway Affected by Mining in Extra Thick Coal Seam. Coal Technology, 39(06), 8-11. Doi:10.13301/j.cnki.ct.2020.06.003 